\title{
Primer estudio experimental sobre los efectos de la digestión en restos esqueléticos de murciélagos (Mammalia: Chiroptera)
}

\author{
Patricia CANALES-BRELLENTHIN ${ }^{1,3 *}$, Yolanda FERNÁNDEZ-JALVO ${ }^{2}$ \& Paloma SEVILLA
}

\footnotetext{
${ }^{1}$ Departamento de Geodinámica, Estratigrafía y Paleontología. Universidad Complutense de Madrid. C/José Antonio Novais, 12, 28040 Madrid, Spain; pcanal01@ucm.es; psevilla@ucm.es

${ }^{2}$ Departamento de Paleobiogía. Museo de Ciencias Naturales de Madrid, C/ José Gutiérrez Abascal, 2, 28006 Madrid, Spain; yfj@mncn.csic.es

${ }^{3}$ Transdiciplinary Center for Quaternary Research, Instituto de Ciencias de la Tierra, Facultad de Ciencias, Universidad Austral de Chile, Casilla 567, Valdivia Chile

* Corresponding author
}

Canales-Brellenthin, P., Fernández-Jalvo, Y. \& Sevilla, P. 2018. Primer estudio experimental sobre los efectos de la digestión en restos esqueléticos de murciélagos (Mammalia: Chiroptera). [First experimental study on the effects of digestion on bat (Mammalia, Chiroptera) skeletal elements]. Spanish Journal of Palaeontology, 33 (2), 345-362.

Manuscript received 20 December 2017

Manuscript accepted 26 November 2018

(C) Sociedad Española de Paleontología ISSN 2255-0550

\section{ABSTRACT}

Taphonomic studies dealing with small mammals do not usually consider bats. Therefore, the degree to which bat bones are modified by predation and other taphonomic agents are largely unknown. Here we present the results obtained from a set of experiments developed to approach this issue, focusing initially on the effect of digestion. For this purpose several bat bones and teeth were exposed to $\mathrm{HCl}$ and to two different proteolithic enzymes. The experiments showed that bat bones are altered by acidic and enzymatic attack in a similar way as the bones of other small mammals. However, some patterns were observed in the teeth that had not been previously described in other groups. Thus, both the intensity of alteration in a tooth and the way in which it advanced during the process varied depending on whether it was an upper or lower tooth, its size or its position in the tooth-row.

Keywords: Experimental study, small mammals, Chiroptera, digestion, proteolithic enzymes, acidic attack, hydrochloric acid.

\section{RESUMEN}

Los estudios tafonómicos de micromamíferos no suelen incluir muestras de quirópteros. Debido a esto, los patrones de alteración producidos por depredación y otros agentes tafonómicos son, en gran parte, desconocidos. Aquí, presentamos un conjunto de experimentos desarrollados para abordar este tema, centrándonos inicialmente en la digestión. Para este propósito, se expusieron diferentes huesos y dientes de murciélagos a ácido clorhídrico y dos enzimas proteolíticas diferentes para simular la digestión. Los experimentos han demostrado que los huesos largos de murciélagos son alterados por el ataque ácido y enzimático de forma similar a los huesos de pequeños mamíferos. Sin embargo, algunos patrones de alteración observados en los dientes, no habían sido descritos previamente para otros grupos. Así, se observaron variaciones en la alteración en dientes, tanto en intensidad como en la progresión de la alteración durante el proceso, dependiendo de si se trataba de un diente superior o inferior, de su tamaño o de su posición en la fila dentaria.

Palabras clave: Estudio experimental, micromamíferos, Chiroptera, digestión, enzima proteolítica, ataque ácido, ácido clorhídrico. 


\section{INTRODUCCIÓN}

El valor evolutivo, biocronológico y paleoecológico de los micromamíferos fósiles ha propiciado el desarrollo de numerosos estudios tafonómicos centrados en indagar los procesos que conducen a la formación de sus asociaciones fósiles (Raczynski \& Ruprecht, 1974; Dodson \& Wexlar, 1979; Lowe, 1980; Fisher, 1981; Denys, 1985; Andrews, 1990; Crandall \& Stahl, 1995; Fernández-Jalvo et al., 1998; Williams, 2001; Terry, 2004). Ya los primeros estudios descriptivos y analíticos concluyen que la mayoría de estas asociaciones fósiles de micromamíferos son el resultado de la acumulación de restos de alimentación de diferentes depredadores (Mellett, 1974; Denys, 1985). Estudios acerca de los efectos de la ingestión y digestión en los restos óseos de presas consumidas, han proporcionado criterios que permiten distinguir con relativa fiabilidad si los restos contenidos en una asociación fósil son producto de la depredación o si las alteraciones que muestran tienen otro origen (ej. Fisher, 1981; Denys, 1985; Andrews, 1990; Fernández-Jalvo \& Andrews, 1992; Fernández et al., 2017). Llegar a esta conclusión no es trivial, ya que afecta al valor interpretativo de la asociación fósil y a la fiabilidad de los resultados de su estudio. El poder reconocer los procesos tafonómicos, ha favorecido el incremento de estudios actualísticos y experimentales (Fernández-Jalvo et al., 2014, 2016; Fernández et al., 2017; Boblitt et al., 2018) que pretenden analizar de forma individualizada cada uno de los procesos involucrados en la alimentación de los depredadores, así como sus consecuencias en los restos óseos no digeridos (selección de la presa, procesamiento previo a la digestión, diferentes tipos y condiciones de digestión, etc). Todo ello ha abierto un nuevo campo en la investigación tafonómica, con la experimentación actualística como protagonista.

Sin embargo, pese a lo activo de este campo de investigación, los estudios actualísticos de procesos tafonómicos en micromamíferos no suelen incluir muestras de quirópteros. Aunque los restos fósiles de murciélagos son elementos comunes en las asociaciones fósiles de cuevas y sistemas cársticos, se suele asumir que su presencia es el resultado de la mezcla de sus restos con los de otros microvertebrados, que ocupan sus mismos hábitats de forma natural, procedentes de la alimentación de un depredador. Sin embargo, en estos emplazamientos los restos de murciélagos pueden ser tanto el producto de la muerte in situ (Pérez Ripoll, 2016) como el producto de la depredación por parte de depredadores que frecuenten la cueva y que incluyan ocasionalmente murciélagos en su dieta (Ruprecht, 1979; Pérez Barbería, 1991; Kowalski, 1995; Sommer et al., 2005; Rosina \& Shokhrin, 2011). Esto exige la búsqueda de criterios tafonómicos que ayuden a separar los elementos autóctonos de los elementos introducidos por depredación, pues ello puede repercutir en las interpretaciones paleoambientales inferidas a partir de la asociación de micromamíferos.

En este trabajo se aborda por la primera vez un estudio tafonómico sobre restos de murciélagos en la búsqueda de patrones de alteración causados por la digestión. Para ello, se han realizado experimentos de laboratorio sometiendo dientes y restos óseos a la acción de ácido clorhídrico $(\mathrm{HCl})$ y enzimas proteolíticas (siguiendo protocolos previamente desarrollados por otros autores, como Denys et al., 1995; Fernández-Jalvo et al., 2014). Los patrones observados han proporcionado por primera vez una herramienta comparativa para el análisis e interpretación de alteraciones tafonómicas observadas en los restos fósiles de quirópteros en los que haya sospecha de haber estado sometidos a digestión.

\section{MATERIAL Y MÉTODOS}

Se expusieron en el laboratorio a restos óseos de murciélagos actuales a condiciones ácidas y actividad enzimática con el fin de simular la digestión estomacal. Para ello se recolectaron cadáveres actuales de murciélagos de distintas localidades, cuya muerte se debió a causas naturales y no a la depredación. Para la realización de la limpieza de las carcasas no se empleó ningún tratamiento químico, aplicándose solamente agua destilada a las carcasas con la finalidad de reblandecer los tejidos y separarlos de los huesos. El experimento se realizó con un detallado protocolo de actuación con documentación gráfica de cada elemento anatómico antes de los experimentos y después de cada exposición, con el fin de describir y caracterizar la secuencia de modificación de estos elementos. Para la nomenclatura dental se siguió a Sevilla (1988) con modificaciones. Las abreviaturas utilizadas en el texto son: HCl: ácido clorhídrico; $\mathbf{M}^{1}, \mathbf{M}^{2} \mathbf{y} \mathbf{M}^{3}$ : primer, segundo y tercer molar superior respectivamente; $\mathbf{M}_{1}, \mathbf{M}_{2} \mathbf{y} \mathbf{M}_{3:}$ primer, segundo y tercer molar inferior respectivamente.

El experimento se llevó a cabo en el Laboratorio de Tafonomía Experimental del Museo Nacional de Ciencias Naturales (MNCN-CSIC) y el Laboratorio del Departamento de Paleontología de la Universidad Complutense de Madrid.

Se separaron elementos craneales y postcraneales de murciélagos, que consisten en cráneos, mandíbulas, cápsulas óticas, fémures y húmeros. Con el fin de observar si existen diferencias respecto a la edad y tamaño, se seleccionaron los elementos craneales de 3 tipos: 1) individuos adultos: cráneos y mandíbulas con dentición definitiva completa con desgaste, de la especie Myotis myotis (Borkhausen, 1797) de la Cueva de Azokh, en Nogorno-Karabakh (Cáucaso Menor); 2) individuos juveniles: cráneos y mandíbulas con dentición en proceso 
final de eclosión y sin desgaste de la especie M. myotis recolectados en la Cueva de los Murciélagos, en Pinilla del Valle, Madrid; y 3) adulto de talla pequeña: en este caso se ha seleccionado la especie Pipistrellus pipistrellus (Schreber, 1774) por tener una talla considerablemente menor a la de M. myotis. El material provino de Estepona (Málaga), donde su cadáver fue recolectado en el suelo en un espacio abierto.

Además, con el fin de abarcar la totalidad de los posibles hallazgos obtenidos en yacimientos fósiles, se ha incluido un total de 16 dientes sueltos (Fig. 1). Se trata de caninos, premolares y molares extraídos de cráneos y mandíbulas de los individuos de M. myotis, tanto de los individuos adultos (dientes con raíces cerradas y facetas de desgaste) como de los juveniles (dientes con raíces abiertas y sin desgaste o desgaste incipiente).

Los elementos craneales y postcraneales fueron separados en dos grupos. Para ello, los cráneos y mandíbulas fueron divididos en sus mitades, proporcionando una hemimandíbula y una hemimaxila del mismo individuo para cada grupo. Así, cada grupo contenía un total de 16 elementos craneales, que consistían en hemimandíbulas, hemimaxilas, cócleas y dientes sueltos, y 2 elementos postcraneales, un húmero y un fémur (Tabla 1). Ambos grupos se sometieron a una exposición ácida y una exposición enzimática, realizando revisiones periódicas en cada exposición. Todos los elementos fueron fotografiados previa y posteriormente a cada una de las exposiciones utilizando una cámara digital Leica DFC420 acoplada a una lupa Leica MZ16 A.
Para cada una de las exposiciones se siguieron los protocolos descritos a continuación (Tabla 2):

Tabla 2. Resumen de los protocolos utilizados para el experimento de digestión en quirópteros. Exposición Ácida: protocolo común para ambos grupos, empleado con el fin de afectar los componentes mineralizados de los elementos. Se siguió para ello el "protocolo 1" de Denys et al. (1995) con modificación. Exposición Enzimática: efectuada para afectar el componente orgánico de los elementos. Grupo 1- Siguiendo el "protocolo 2" de Denys et al. (1995) para la enzima Pronase $\left(\right.$ Roche $\left.^{\circledR}\right)$. Grupo 2- Protocolo de exposición enzimática elaborado para este trabajo utilizando la enzima Olexa $\left(\right.$ Novozymes Bioenergy $\left.^{\circledR}\right) . T^{0}=$ temperatura; Hrs = horas.

\begin{tabular}{|c|c|c|c|}
\hline & & Grupo 1 & Grupo 2 \\
\hline \multirow{4}{*}{$\begin{array}{l}\text { Protocolo de } \\
\text { exposición ácida }\end{array}$} & & $\mathrm{HCl}$ & $\mathrm{HCl}$ \\
\hline & $\mathrm{pH}$ & 2 & 2 \\
\hline & $\mathrm{T}^{\mathrm{o}}$ & $20^{\circ} \mathrm{C}$ & $20^{\circ} \mathrm{C}$ \\
\hline & Hrs. & 14 & 14 \\
\hline \multirow{3}{*}{$\begin{array}{l}\text { Protocolo de } \\
\text { exposición } \\
\text { enzimática }\end{array}$} & & Pronase & Olexa \\
\hline & Solución & Acetato de Calcio & $\mathrm{HCl}$ \\
\hline & $\mathrm{pH}$ & 7,4 & 3,8 \\
\hline \multirow[t]{3}{*}{ Concentración } & & $1 \mathrm{mg} / 1 \mathrm{ml}$ & $20 \mathrm{ml} / 80 \mathrm{~m}$ \\
\hline & $\mathrm{T}^{\mathrm{o}}$ & $40^{\circ} \mathrm{C}$ & $30^{\circ} \mathrm{C}$ \\
\hline & Hrs & 12 & 16 \\
\hline
\end{tabular}

Tabla 1. Número y tipo de elementos óseos utilizados en el experimento. Estos fueron separados en dos grupos de modo que ambos tuvieran el mismo número de elementos. Para hacer ambos grupos lo más similar posibles, los cráneos y mandíbulas de un mismo individuo fueron separados en sus respectivas mitades. Luego se designó una hemimaxila y una hemimandíbula a cada grupo.

\begin{tabular}{|c|c|c|c|c|c|c|c|}
\hline & \multicolumn{3}{|c|}{ Grupo 1} & \multicolumn{3}{|c|}{ Grupo 2} & \multirow[t]{2}{*}{ Total } \\
\hline & Adulto & Juvenil & Pequeño & Adulto & Juvenil & Pequeño & \\
\hline & M. myotis & M. myotis & P. pipistrellus & M. myotis & M. myotis & P. pipistrellus & \\
\hline Hemimaxilas & 1 & 1 & 1 & 1 & 1 & 1 & 6 \\
\hline Hemimandíbulas & 1 & 1 & 1 & 1 & 1 & 1 & 6 \\
\hline Caninos sueltos & 1 & 2 & 0 & 1 & 2 & 0 & 6 \\
\hline Molares sueltos & 2 & 2 & 0 & 2 & 2 & 0 & 8 \\
\hline Premolares & 1 & 0 & 0 & 0 & 1 & 0 & 2 \\
\hline Húmeros & 1 & 0 & 0 & 1 & 0 & 0 & 2 \\
\hline Fémures & 1 & 0 & 0 & 1 & 0 & 0 & 2 \\
\hline Cápsulas óticas & 1 & 1 & 0 & 1 & 1 & 0 & 4 \\
\hline Total & 8 & 8 & 2 & 8 & 8 & 2 & 36 \\
\hline
\end{tabular}




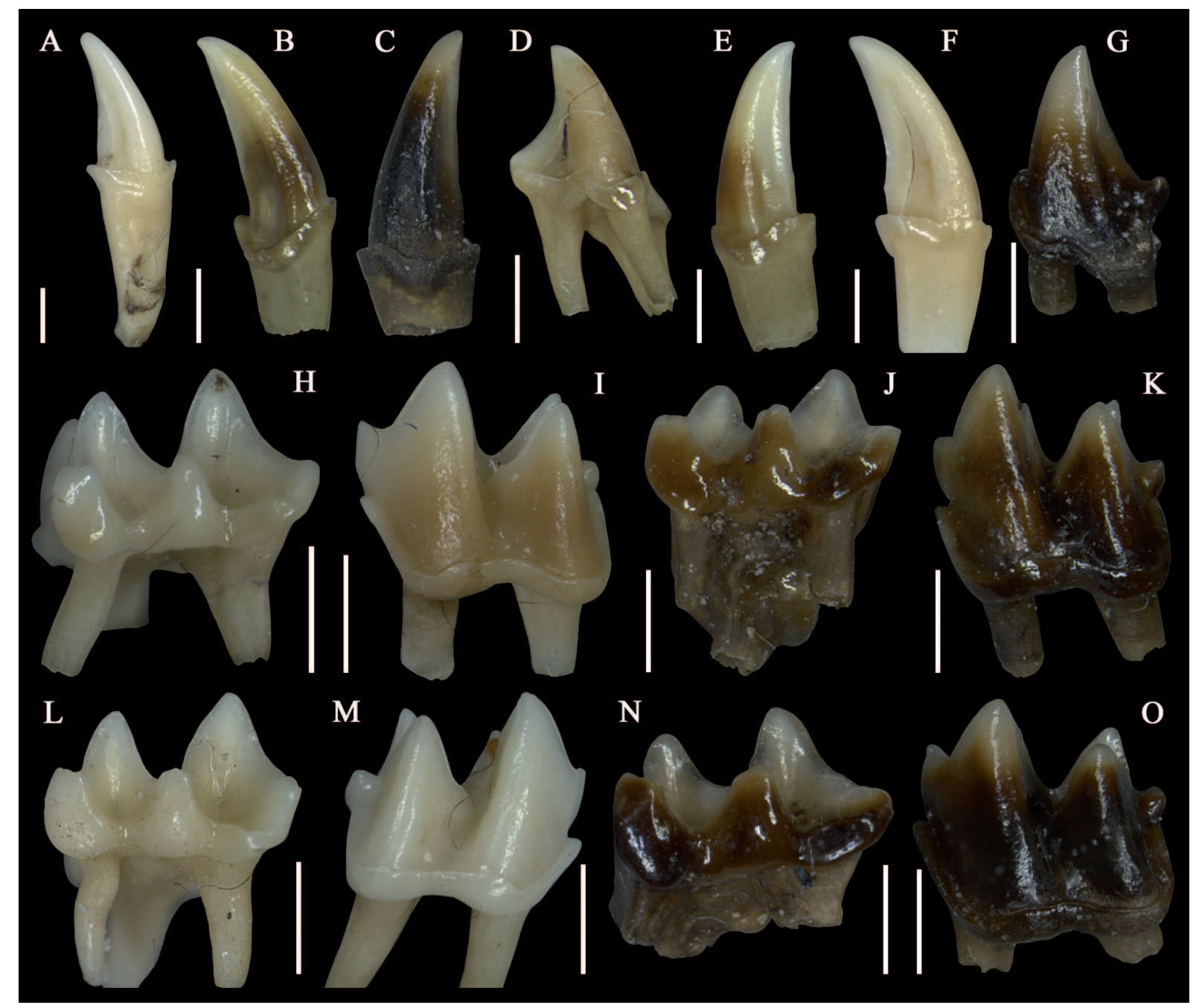

Figura 1. Dientes sueltos de Myotis myotis antes de ser sometidos al experimento. a-d) Caninos y premolar sueltos del Grupo 1. e-g) Caninos y premolar del Grupo 2. h-k) Molares de adultos y juveniles del Grupo 1. l-o) Molares de adultos y juveniles del Grupo 2. (a, f, h, i, l, m) Dentición adulta, extraída de individuos obtenidos en la Cueva de Azokh. (b, c, e, $\mathbf{g}, \mathbf{j}, \mathbf{k}, \mathbf{n}, \mathbf{o})$ Dentición juvenil, extraída de individuos obtenidos en la Cueva de los murciélagos. Escalas = 1mm.

\subsection{Protocolo de exposición ácida}

Con el fin de alterar los componentes minerales de los elementos, ambos grupos fueron sometidos a una exposición ácida previa a la exposición enzimática (Tabla 2). Para ello nos basamos en el trabajo de Denys et al. (1995) que emplea $\mathrm{HCl}$ pH 1 en su exposición ácida ("Protocolo 1" en su trabajo). Sus resultados corresponden a una modificación similar a la producida por falconiformes (rapaces diurnas), que producen una modificación Fuerte en la clasificación de Andrews (1990). Hemos incluido modificaciones a su protocolo, ajustando la acidez del ácido clorhídrico a valores $\mathrm{pH}$ del jugo gástrico de lechuza común después de la regurgitación y antes de la alimentación (Smith \& Richmond, 1972), ya que es cuando está completamente lista para consumir una nueva presa. Con ello se pretendía producir una modificación menor que la obtenida por Denys et al. (1995) y lo más similar posible a la de rapaces nocturnas, ya que dada las conductas habituales de los murciélagos (voladores nocturnos), éstas son uno de sus principales depredadores oportunistas (Ruprecht, 1979; Hill \& Smith, 1984; Pérez Barbería, 1991; Kowalski, 1995; Sommer et al., 2005; Rosina y Shokhrin, 2011). Así, en la exposición ácida (Tabla 2) hemos empleado $\mathrm{HCl} \mathrm{pH} 2$ durante 14 horas a una temperatura de $20^{\circ} \mathrm{C}$, simulando los rasgos digestivos de la lechuza.

\subsection{Protocolo de exposición enzimática con Pronase - Grupo 1}

La experimentación enzimática del Grupo 1 se realizó siguiendo el "Protocolo 2" de Denys et al. (1995), exponiendo las muestras a la enzima Pronase (Roche ${ }^{\circledR}$ ) con una concentración de $1 \mathrm{mg} / \mathrm{ml}$ disuelta en una solución tampón de acetato de calcio (pH 7,4). También hemos 
incluido una modificación a su protocolo, ajustando las horas de exposición, tras confirmar durante la revisión de las muestras (realizadas cada 4 horas bajo lupa binocular) que los elementos mostraban modificaciones significativas a las 12 horas.

\subsection{Protocolo de exposición enzimática con Olexa - Grupo 2}

En la experimentación con el Grupo 2 hemos empleado una enzima nueva, Olexa (proporcionada por UNIVAREUROPE, fabricada en los laboratorios Novozymes Bioenergy). Ésta consiste en una endoproteasa que hidroliza diversos enlaces peptídicos y tiene la particularidad de ser ácido tolerante, lo que la hace más similar a la pepsina liberada en el estómago. La máxima efectividad de Olexa, indicada por el fabricante, se obtiene entre $\mathrm{pH} 3,7$ y 5,8 en un rango de temperaturas entre 28 a $36^{\circ} \mathrm{C}$. Dada sus características la preparación de Olexa se ha realizado diluyendo $20 \mathrm{ml}$ de Olexa en $80 \mathrm{ml}$ de ácido clorhídrico $\mathrm{pH} 3.8$ (Tabla 2). Se ha seleccionado este $\mathrm{pH}$ tanto por el rango recomendado por el fabricante como por la variación del pH del jugo gástrico de lechuza común tras la ingestión de su alimento (Smith \& Richmond, 1972). El tiempo de exposición de los elementos anatómicos de quiróptero en Olexa fue de 16 horas a una temperatura de $30^{\circ} \mathrm{C}$.

\section{RESULTADOS}

\subsection{Dientes sueltos}

Los dientes sueltos del Grupo 1, expuestos a la enzima Pronase, presentaron pérdida del esmalte con exposición de la dentina alrededor de toda la base de la corona, en los caninos y el premolar, tanto en adulto (Figs. 2a-b) como en juveniles (Figs. 2c-h). El canino de adulto, además presenta su cara labial desprovista completamente de esmalte (Fig. 2a). Todos los caninos presentan pérdida de esmalte con exposición de la dentina a lo largo del borde incisal, desde el cíngulo hasta la cúspide (Figs. 2b-c, 2f). Los individuos juveniles resultaron con la raíz completamente disuelta, llegando a perder completamente el cíngulo. Por otro lado, el canino de adulto presenta su raíz intacta con disolución parcial del cíngulo (Fig. 2a).

Todos los molares expuestos a la enzima Pronase han perdido esmalte en sus cúspides (Fig. 3). Los molares superiores (Figs. 3a-f) perdieron completamente el esmalte de las coronas por la cara labial (Figs. 3b, 3e), mientras que los inferiores (Figs. 3g-l) lo hicieron por la cara lingual (Figs. 3h, 3k). El molar superior de adulto también ha perdido esmalte por su cara lingual. En esta cara solamente ocurre la pérdida en su base, trazándose un pico de dentina expuesta en el margen prominente del diente (Fig. 3a). Los molares de juveniles, tanto el superior como el inferior,

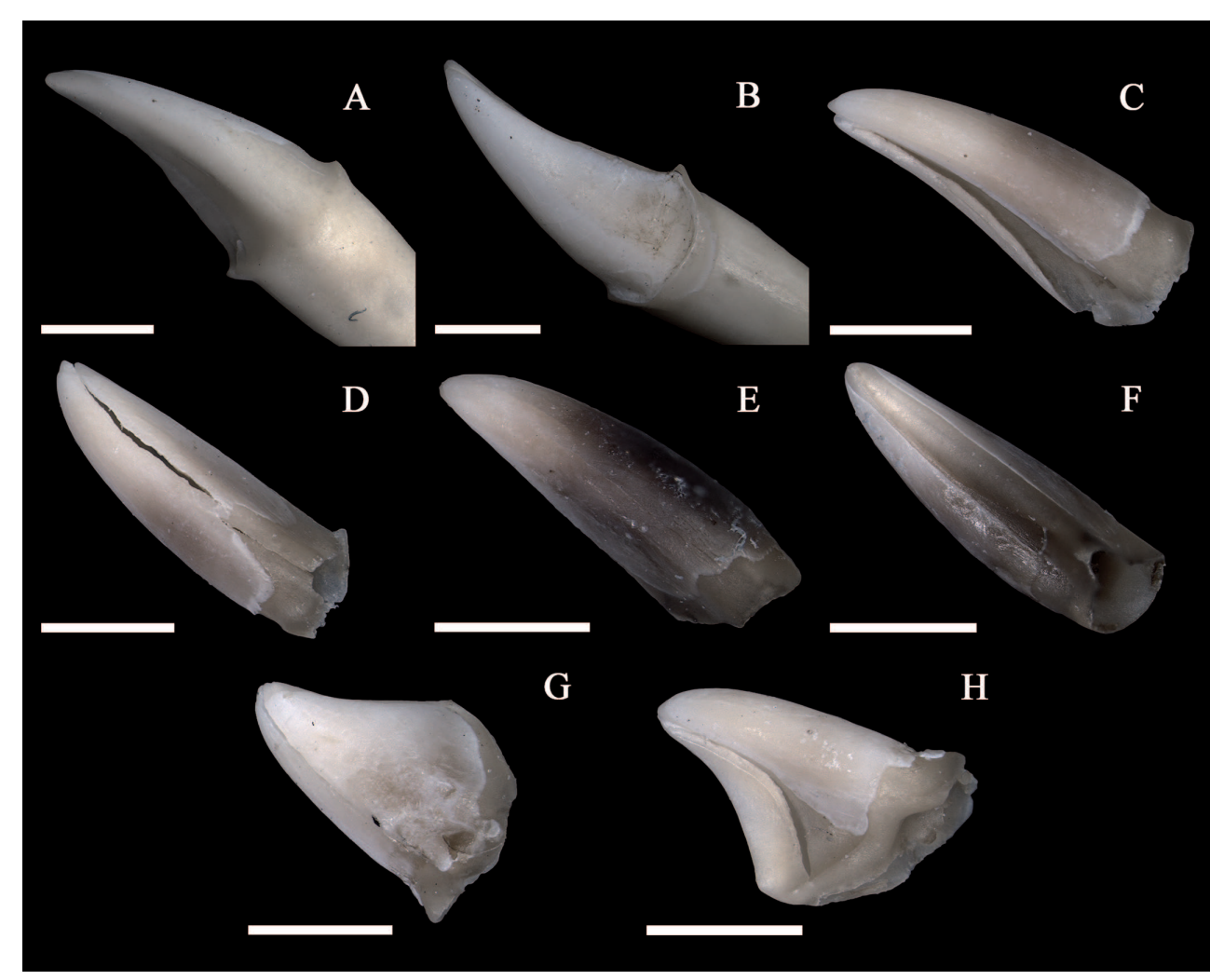

Figura 2. Caninos y premolar sueltos de Myotis myotis del Grupo 1, expuestos a la enzima Pronase. a-b) Canino superior adulto. c-f) Caninos superiores juvenil. g-h) Premolar superior adulto. Escalas $=1 \mathrm{~mm}$. 
presentaron pérdida parcial del esmalte en los valles, principalmente alrededor de las crestas (Figs. 3e, 3k). Los molares de adultos, por su parte, muestran una pérdida mayor de esmalte en los valles, presentando únicamente islas de esmalte (Figs. 3b, 3h). Los molares sueltos expuestos a la enzima Pronase presentaron disolución de componentes estructurales, perdiendo por completo las raíces y los cíngulos se encuentran completamente disueltos en superiores y parcialmente disueltos en inferiores. En estos últimos, el cíngulo labial muestra eliminación total del esmalte en adulto (Fig. 3g), en cuanto al del juvenil (Fig. 3j) aún presenta algo de esmalte.
Después de la exposición a la enzima Olexa (Grupo 2), solamente el canino juvenil muestra pérdida de esmalte en la base de la corona por su cara postero-lingual (Fig. $4 b)$. El canino de adulto presenta pérdida del esmalte con exposición de la dentina a lo largo del borde incisal (Fig. 4e), mientras que el premolar de juvenil presenta la pérdida de esmalte en el ángulo agudo (Fig. 4h). Esta exposición de la dentina puede describirse como una delgada banda de dentina que va desde el cíngulo hasta la cúspide. Además, presentan pérdida de esmalte en el cíngulo, que se presenta completa en premolares (Figs. 4f-h) y parcial en caninos (Figs. 4a-e).

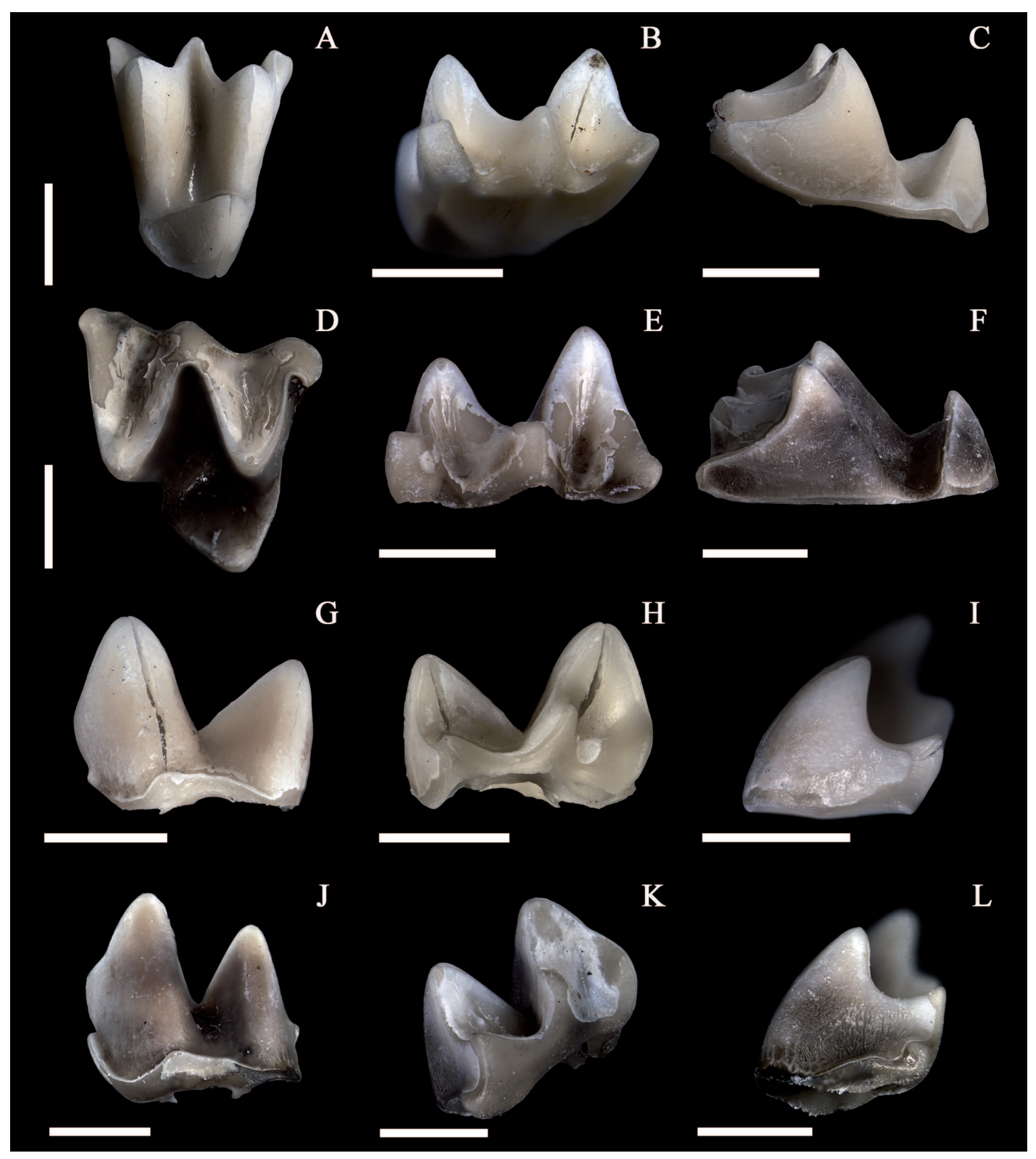

Figura 3. Molares superiores e inferiores sueltos de Myotis myotis del Grupo 1, expuestos a la enzima Pronase. a-c) Molar superior adulto. d-f) Molar superior juvenil. g-i) Molar inferior adulto. j-I) Molar inferior juvenil. Escalas $=1 \mathrm{~mm}$. 

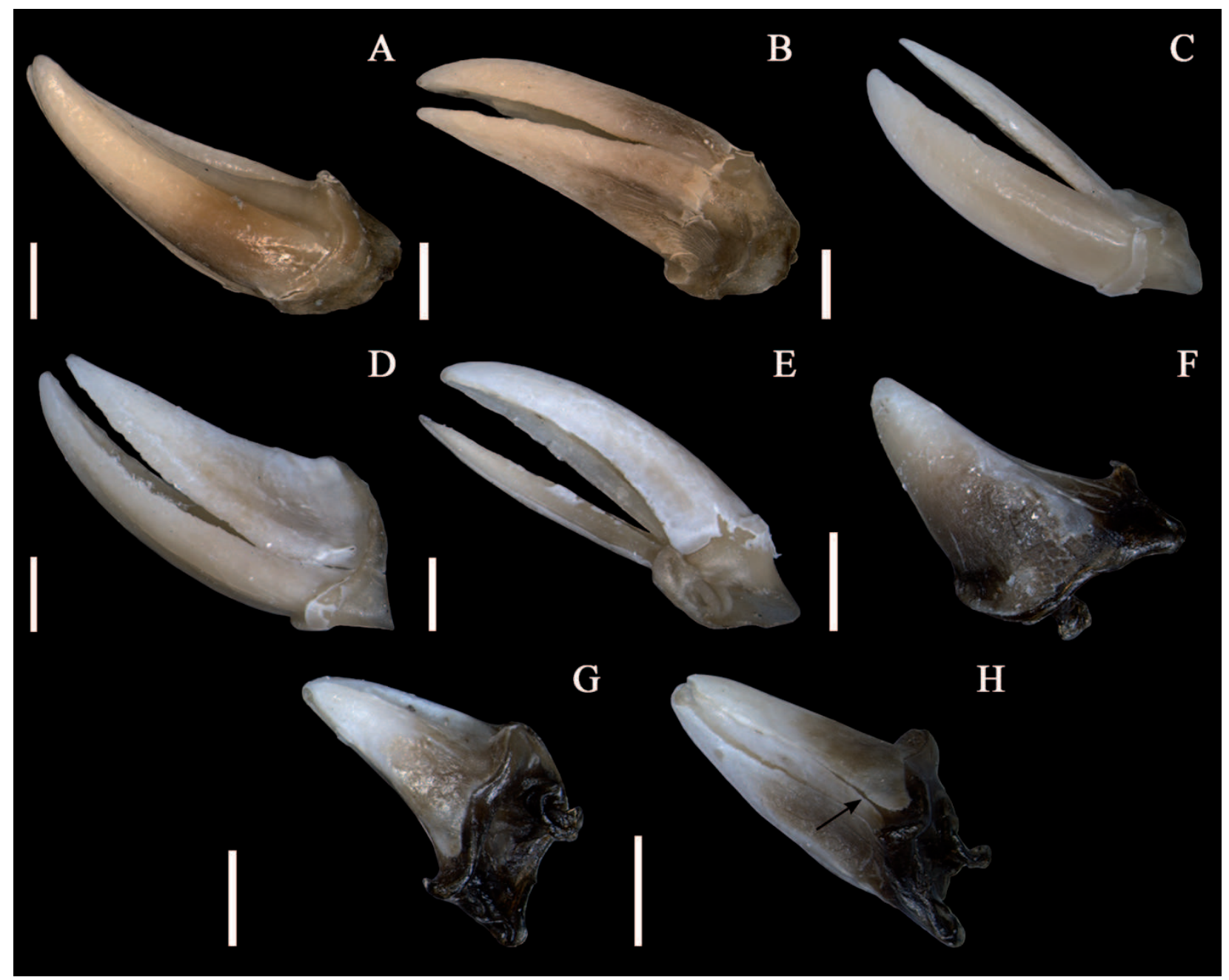

Figura 4. Caninos y premolar sueltos de Myotis myotis del Grupo 2, expuestos a la enzima Olexa. a-b) Canino superior juvenil. c-e) Canino superior adulto. f-h) Premolar inferior juvenil; Flecha: delgada banda de dentina. Escalas $=1 \mathrm{~mm}$.

Al igual que con la enzima Pronase, la alteración de la corona en los molares comienza por la cara labial en dientes superiores y por la lingual en inferiores. Sin embargo, con Olexa el esmalte no ha desaparecido completamente en ningún caso. En individuos juveniles (Figs. 5e, 5k) la pérdida de esmalte se produjo en las cúspides y en la base de la corona. En los molares de adultos (Figs. 5a-c, 5gi), en cambio, la pérdida del esmalte produjo además una banda de dentina incompleta en el mesostilo del molar superior y completa en para y entocónido en el molar inferior (Fig. 5h). Sumado a esto, el esmalte de las crestas presenta picoteado (Fig. 5a).

También se produjo reducción del esmalte en el cíngulo, completa en molares superiores (Figs. 5a-f) y parcial en inferiores (Figs. 5g-1), y pérdida parcial o apical de las raíces.

Todos los dientes sueltos del experimento han perdido esmalte en sus cúspides, con excepción de un molar superior juvenil del Grupo 2 (Figs. 5d-f).

\subsection{Elementos craneales y dentición in situ}

\subsubsection{Maxilares}

En todos los casos y en ambos grupos la dentición maxilar presentó menor grado de modificación que la mandibular.

Tanto elementos del Grupo 1 (Pronase) como del Grupo 2 (Olexa) mostraron modificaciones que pueden ordenarse en secuencia progresiva de modificación. Así, con Olexa, la dentición maxilar de individuos juveniles de Myotis myotis no presentó alteración (Figs. 6a-b), la de los adultos presentó poca modificación, asociada a la faceta de desgaste (Figs. 6c-d) y, finalmente, el grado de modificación más intenso se registra en la dentición maxilar de Pipistrellus pipistrellus (Figs. 6e-f), de menor tamaño. La misma progresión se observó en las hemimaxilas expuestas a la enzima Pronase (Figs. 7a-g), sin embargo, esta enzima se diferencia en que la modificación ocurrida fue más intensa en todos los casos. 


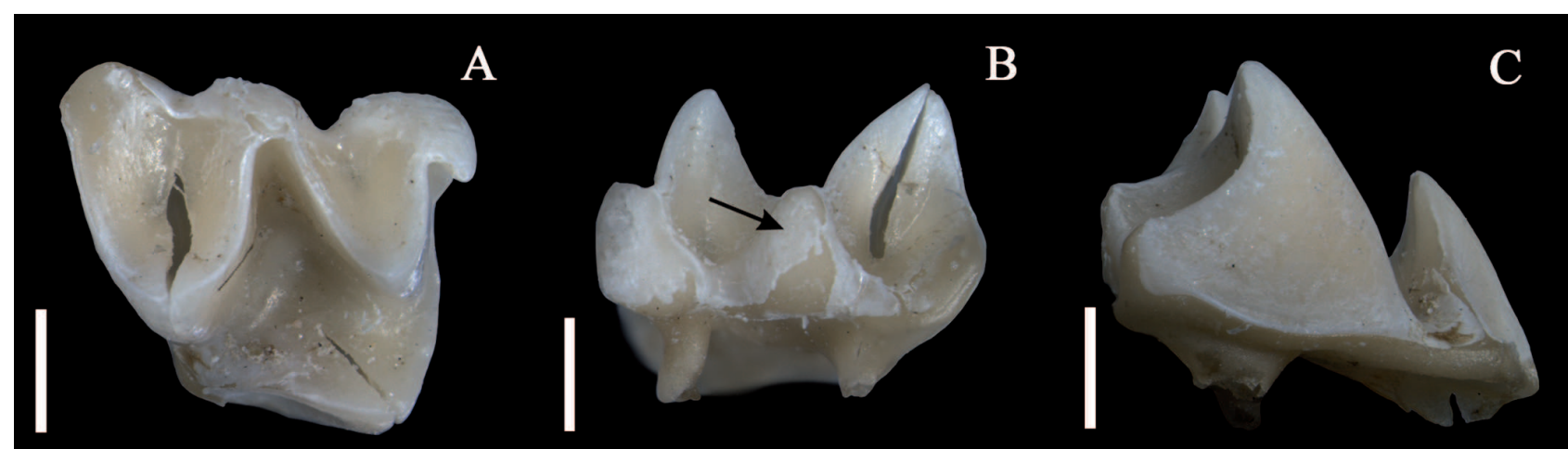

D
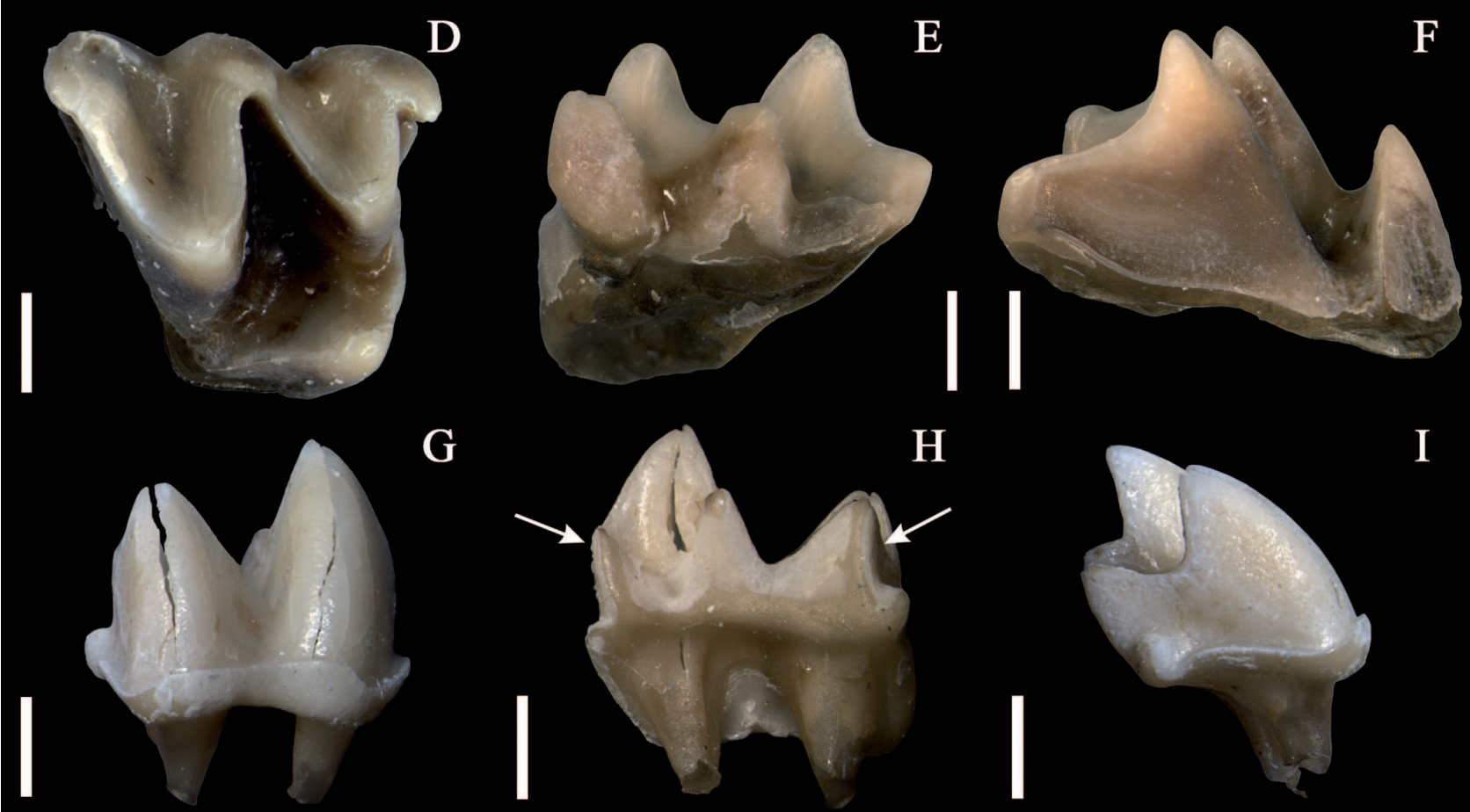

H
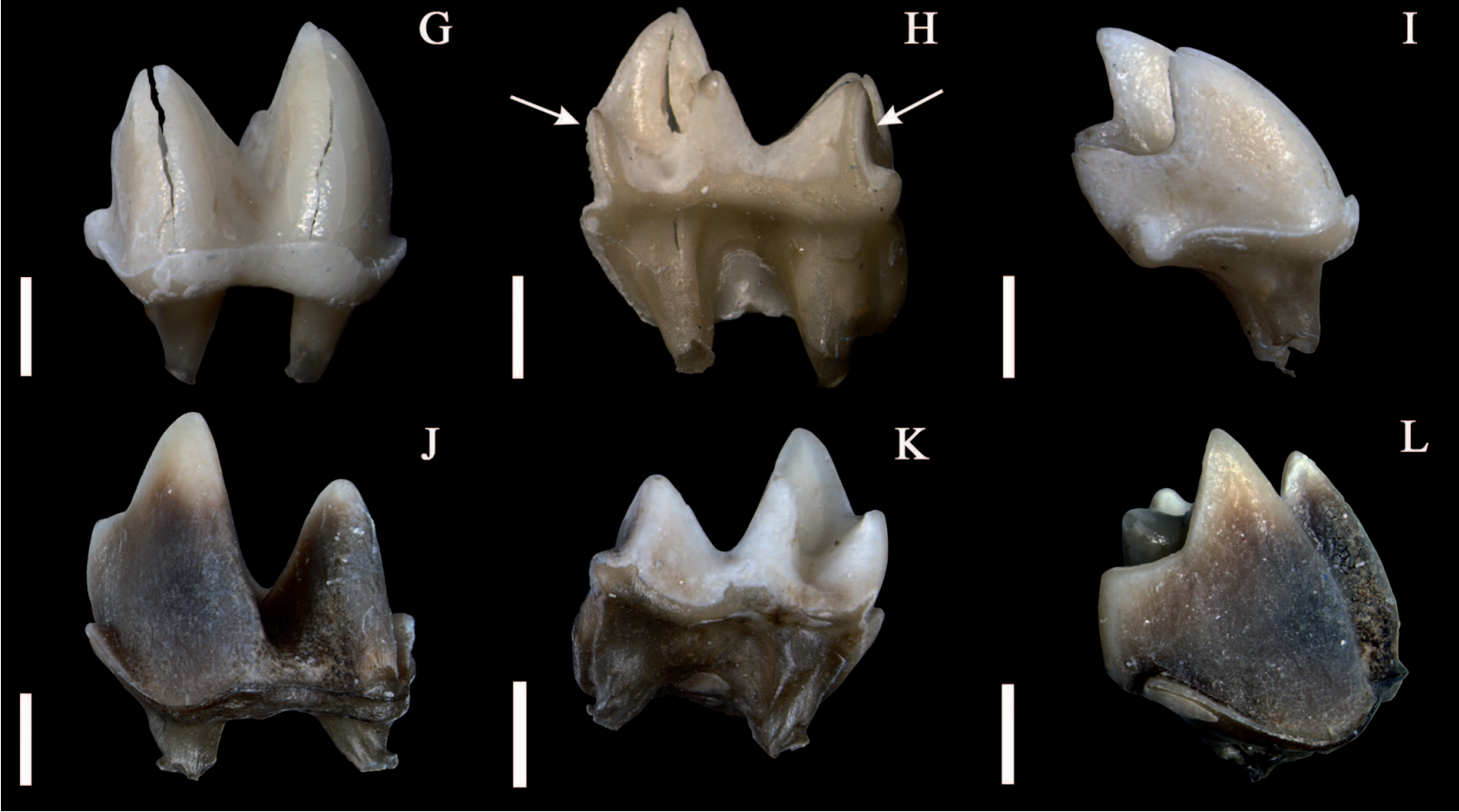

Figura 5. Molares superiores e inferiores sueltos de Myotis myotis del Grupo 2, expuestos a la enzima Olexa. a-c) Molar superior adulto. d-f) Molar superior juvenil. g-i) Molar inferior adulto. j-l) Molar inferior juvenil. Flecha negra: banda de dentina incompleta en el mesostilo. Flechas blancas: banda de dentina en para y entocónido Escalas $=1 \mathrm{~mm}$.

Comparando los individuos caso a caso, la diferencia entre las modificaciones observadas es menos evidente en los individuos de M. myotis. Como ya hemos dicho antes, el individuo juvenil no presentó modificación con la enzima Olexa. Sin embargo, tras la exposición a la enzima Pronase (Figs. 7a-b), el individuo juvenil mostró el grado de modificación más bajo de todo el conjunto. Ésta consiste en superficie mate en la postprotocresta y el cíngulo lingual de $\mathrm{M}^{1}$ y $\mathrm{M}^{2}$ (Fig. 7b). En el caso del individuo adulto, la dentición de la hemimaxila mostró modificaciones relacionadas con el desgaste de los dientes con ambas enzimas. Estas consisten en color blanco mate 


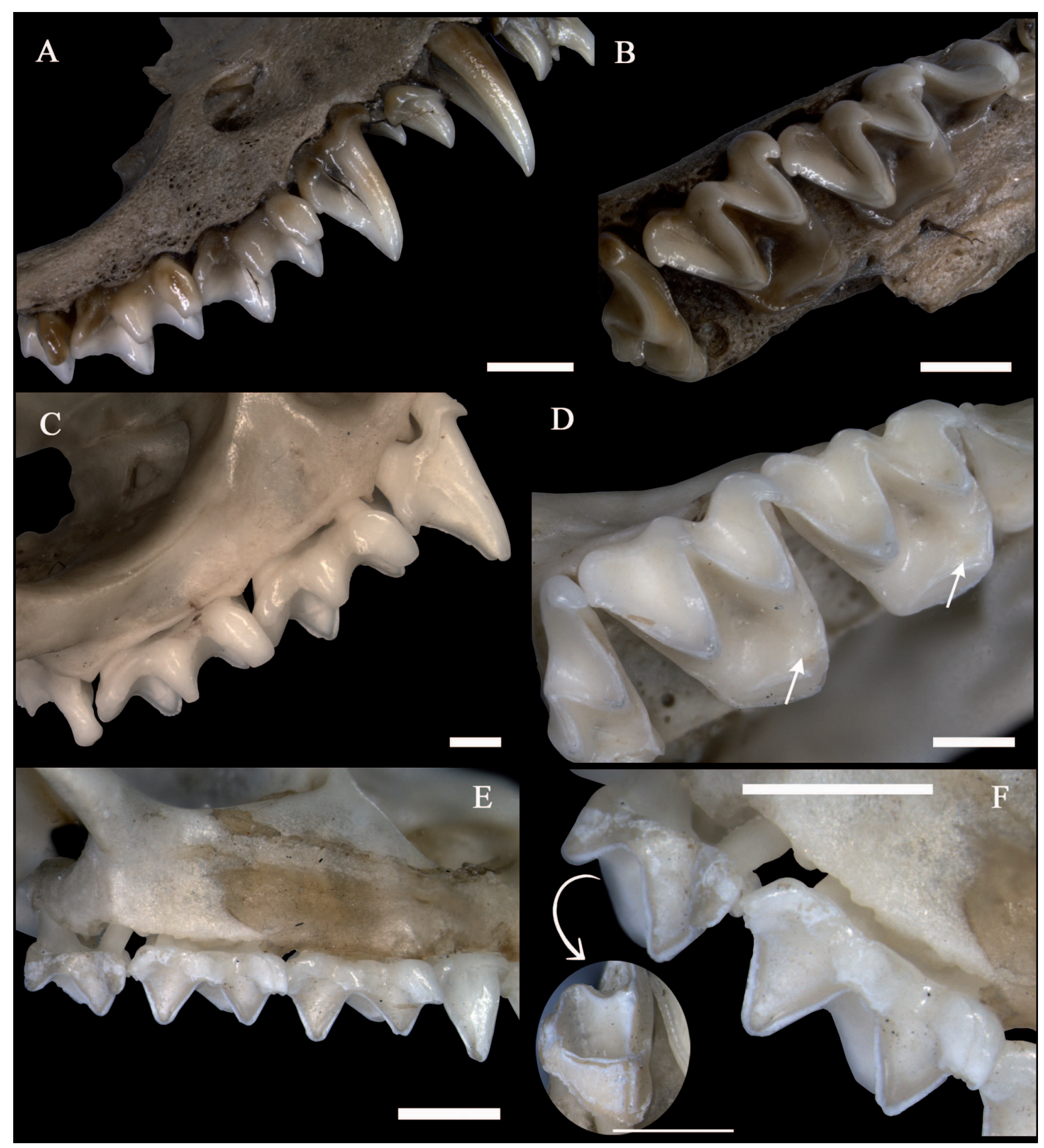

Figura 6. Hemimaxilas del Grupo 2, expuestas a la enzima Olexa. a-b) Myotis myotis juvenil. c-d) Myotis myotis adulto. e-f) Pipistrellus pipistrellus. La foto del círculo (f) indica un detalle de la vista lingual del $\mathrm{M}_{3}$. Flechas: apuntan al paracono, en el cual se aprecia más fácilmente la pérdida del esmalte hacia el valle, en el borde interno de la faceta de desgaste. Escalas $=1 \mathrm{~mm}$.

en las crestas (pre y postparacresta, y pre y postmetacresta) (Figs. 6c, 7c) y pérdida de esmalte en el borde interno de las facetas de desgaste, más evidente en el protocono (Figs. $6 \mathrm{~d}, 7 \mathrm{~d})$. Además, la dentición de la hemimaxila expuesta a Pronase presentó superficie mate en la cara labial de todos los molares y en los alrededores de la faceta de desgaste del protocono de $\mathrm{M}^{2}$ y $\mathrm{M}^{3}$. Con ambas enzimas se observó redondeamiento leve de los bordes de fracturas del cráneo en ambos individuos de $M$. myotis.

En cuanto a $P$. pipistrellus, existe una progresión más clara entre los grados de modificaciones producidos por Olexa (Figs. 6e-f) y los producidos por Pronase (Figs. 7e, 
$7 \mathrm{~g}$ ). Después de la exposición a Olexa, por la cara lingual se pudo observar superficie mate y pérdida de esmalte en cúspides y los bordes más agudos de los cíngulos de todos los dientes (tanto en premolar como en molares). Además, se formó una delgada banda de dentina desde el protocono del $\mathrm{M}^{3}$ (Fig. 6f). En la cara labial en cambio, se observa blanqueamiento con picoteado del esmalte en $\mathrm{M}^{2}$ y $\mathrm{M}^{3}$ (Figs. 6e-f) y en vista oclusal, pérdida del esmalte en todas las cúspides y crestas.

Después de la exposición a la enzima Pronase, la dentición maxilar de P. pipistrellus mostró blanqueamiento y picoteado del esmalte en todos los dientes por su cara labial (Fig. 7e), excepto en $\mathrm{M}^{3}$, que presentó pérdida total del esmalte tanto en la cara labial como en la distal y lingual. En vista lingual, se observó pérdida del esmalte en las cúspides y el cíngulo, además de banda de dentina en protocono y metacónulo de los molares y en los ángulos salientes del canino y premolar (Fig. 7f). En vista oclusal, pérdida de esmalte en crestas y en los valles de para y metacono, donde $\mathrm{M}^{1} \mathrm{y} \mathrm{M}^{2}$ presentaron únicamente islas de esmalte (Fig. 7g), mientras que el $\mathrm{M}^{3}$ ha perdido completamente el esmalte del valle del paracono. Además, ambas enzimas produjeron disolución del arco cigomático y de las fracturas craneales, generando bordes redondeados. Esta disolución también resulta más intensa con Pronase que con Olexa.

\subsubsection{Mandibulas}

La dentición mandibular mostró diferencias más evidentes, en cuanto a los grados de modificación, en todas las variables (tamaño, edad, enzima).

En la hemimandíbula de Myotis myotis juvenil expuesta a Olexa, se observó únicamente superficie mate de la dentición en vista labial (Figs. 8a-b). En cambio, en la dentición mandibular del individuo juvenil expuesta a Pronase (Figs. 9a-b), se observó pérdida de esmalte en el cíngulo de los molares. En vista oclusal, pérdida de esmalte en todas las cúspides y adelgazamiento del esmalte en las créstidas. Finalmente, en vista lingual, además de superficie mate en toda la dentición, se observa pérdida de esmalte en la base de $\mathrm{M}_{3}$.

En la dentición de la hemimandíbula de M. myotis adulto expuesta a Olexa se observó modificación principalmente en la cara lingual y oclusal de $\mathrm{M}_{2}$ y $\mathrm{M}_{3}$ (Figs. 8c-d). La cara labial solo muestra superficie mate en el protocónido e hipocónido del $\mathrm{M}_{3}$. En la cara lingual se observó picoteado y pérdida de esmalte en la base de los $\mathrm{M}_{2}$ y $\mathrm{M}_{3}$ y pérdida de esmalte con formación de banda de dentina incompleta en el metacónido en $\mathrm{M}_{3}$ (Fig. 8c). En vista oclusal se observó pérdida de esmalte en cúspides y borde interno de la faceta de desgaste en las créstidas en $\mathrm{M}_{2}$ y $\mathrm{M}_{3}$, además de un color blanquecino opaco del esmalte alrededor de las facetas de desgaste de todos los molares (Fig. 8d).
En la hemimandíbula de M. myotis adulto expuesto a Pronase (Figs. 9c-d), se producen modificaciones muy similares a las obtenidas con Olexa. Sin embargo, son más intensas ya que esta vez la superficie mate alcanza al $M_{1}$ y el $M_{3}$ presenta una clara banda de dentina en el metacónido (Fig. 9d) y pérdida de esmalte por toda la cara lingual. En vista oclusal, la pérdida del esmalte es mayor, todo el valle del trigónido se encuentra desprovisto de él y el talónido presenta únicamente isla de esmalte. Se presenta, además, una modificación no observada con Olexa, dónde los cíngulos labiales, mesiales y distales de los molares presentaron pérdida del esmalte en los ángulos agudos (Fig. 9c).

En los individuos pequeños (Pipistrellus pipistrellus) expuestos a Olexa (Figs. 8e-g), los molares no presentan modificación por la cara labial (Fig. 8e). El canino en cambio, presenta superficie mate. En la cara oclusal (Fig. 8f) se observó pérdida de esmalte en todas las cúspides y en las créstidas de los molares. Por la cara lingual (Fig. $8 \mathrm{~g}$ ), los molares presentaron pérdida total de esmalte en $\mathrm{M}_{3}$ y parcial en $\mathrm{M}_{1}$ y $\mathrm{M}_{2}$, que conservan islas de esmalte. Por su parte, en caninos y premolares la pérdida de esmalte se observa en el cíngulo lingual y ángulos salientes (Fig. 8g).

La exposición de P. pipistrellus a la enzima Pronase (Figs. 9e-g) ha provocado la pérdida total del esmalte con corrosión de la dentina por la cara lingual y oclusal (valles) de todos los molares (Fig. 9f). Además, la banda de dentina (completa en $M_{2}$ y $M_{3}$ e incompleta en $M_{1}$ ) se advierte ahora en la cara labial (Figs. 9e, 9g), donde además podemos observar pérdida de esmalte en los cíngulos y las cúspides. En el canino la pérdida de esmalte es total, mientras que el premolar conserva islas de esmalte en cara mesial y distal.

Por último, la rama mandibular de las muestras también se vio afectada. Con la enzima Pronase se observó perforación de la fosa mandibular en individuos adultos (Fig. 9c), pérdida de todos los procesos y mayor porosidad del tejido en la rama ascendente y sínfisis mandibular en juveniles (Fig. 9a) y pérdida total de la rama ascendente en individuos de talla pequeña (Fig. 9e). Olexa, en cambio, produjo poca modificación en los procesos mandibulares de los individuos juveniles (Fig. 8a) y perforación de la fosa mandibular en P. pipistrellus (Fig. 8e), sin causar daños en las mandíbulas de adultos.

\subsubsection{Cápsulas óticas}

La cápsula ótica es un elemento bastante desarrollado en quirópteros, sin embargo, su presencia en yacimientos fósiles con murciélagos es bastante escasa, o posiblemente sea obviada en el conteo de elementos esqueléticos. Por ello hemos querido incluirlas en el estudio con el fin de investigar posibles modificaciones ocasionadas por acción de ácidos y enzimas. La cápsula ótica, pese a ser un 


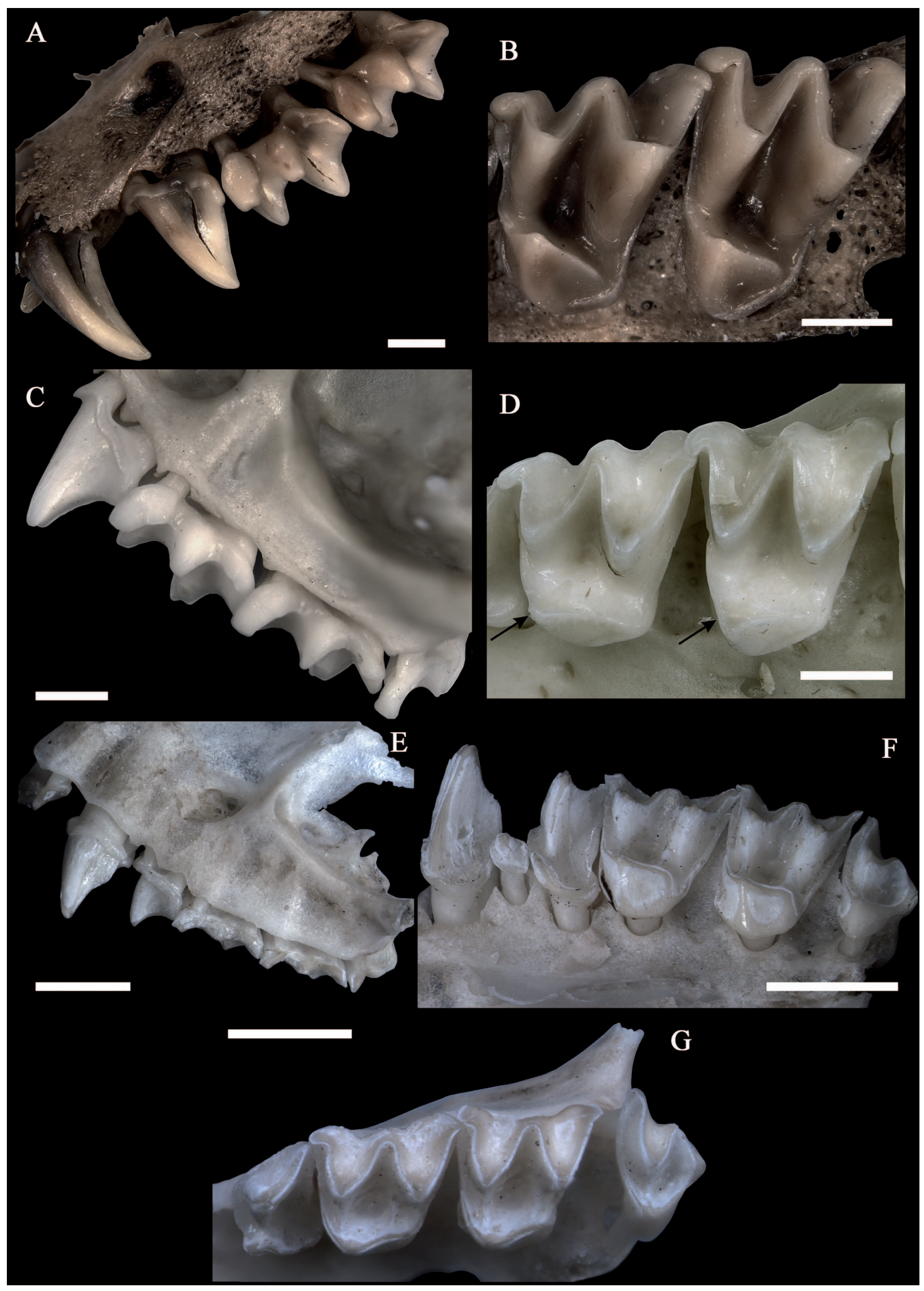

Figura 7. Hemimaxilas del Grupo 1, expuestas a la enzima Pronase. a-b) Myotis myotis juvenil. c-d) Myotis myotis adulto. e-g) vistas labial, lingual y oclusal de Pipistrellus pipistrellus respectivamente. Flechas: apuntan al paracono, en el cual se aprecia más fácilmente la pérdida del esmalte hacia el valle, en el borde interno de la faceta de desgaste. Escalas $=1 \mathrm{~mm}$. 


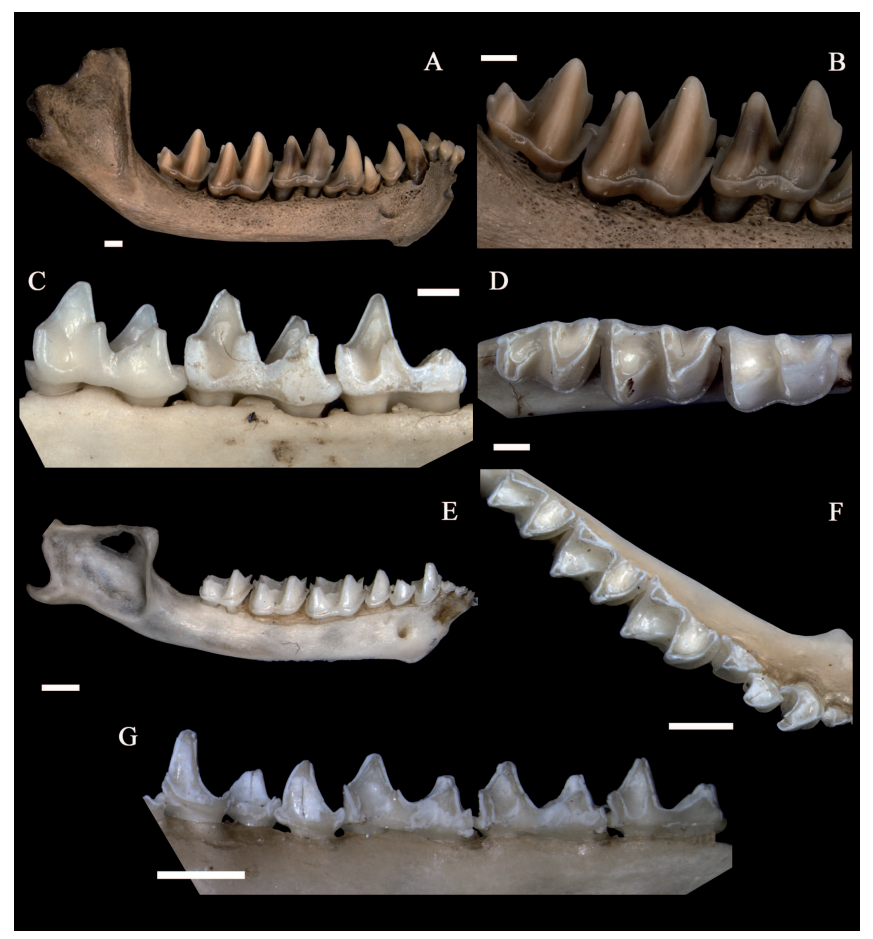

Figura 8. Hemimandíbulas del Grupo 2 expuestas a la enzima Olexa. a-b) Myotis myotis juvenil. c-d) Myotis myotis adulto. e-g) vistas labial, oclusal y lingual de Pipistrellus pipistrellus. Escalas $=1 \mathrm{~mm}$.

elemento delicado, resistió el experimento (Figs. 10a-f). Las cápsulas del Grupo 2, expuestas a la enzima Olexa (Figs. 10a-b), presentaron disolución de los bordes más finos del canal semicircular superior tanto en adultos como juveniles (Figs. 10a-b). En el caso del Grupo 1 (enzima Pronase) han presentado modificaciones respondiendo a la edad, mostrando disolución del canal semicircular lateral en individuos adultos (Figs. 10c-d) y del canal semicircular lateral y posterior en juveniles (Figs. 10e-f).

\subsubsection{Secuencia de modificación}

Una vez finalizado el experimento y observadas las modificaciones producidas en los elementos craneales (Tabla 3), es posible establecer la secuencia de progresión de las modificaciones en la dentición de murciélagos producidas tras la digestión de aves rapaces. Para ellos hemos seguido los siguientes criterios:

La dentición con menos grado de modificación, tras la acción ácida y enzimática, se ha utilizado para establecer el inicio de la secuencia de modificación o "Estadio 1". Para este caso, la escasa alteración observada en la dentición maxilar de ambos individuos de M. myotis ha sido considerada como de las primeras modificaciones observables en los dientes digeridos de murciélagos.

Por el contrario, la dentición con mayor grado de modificación tras el experimento se estableció como último

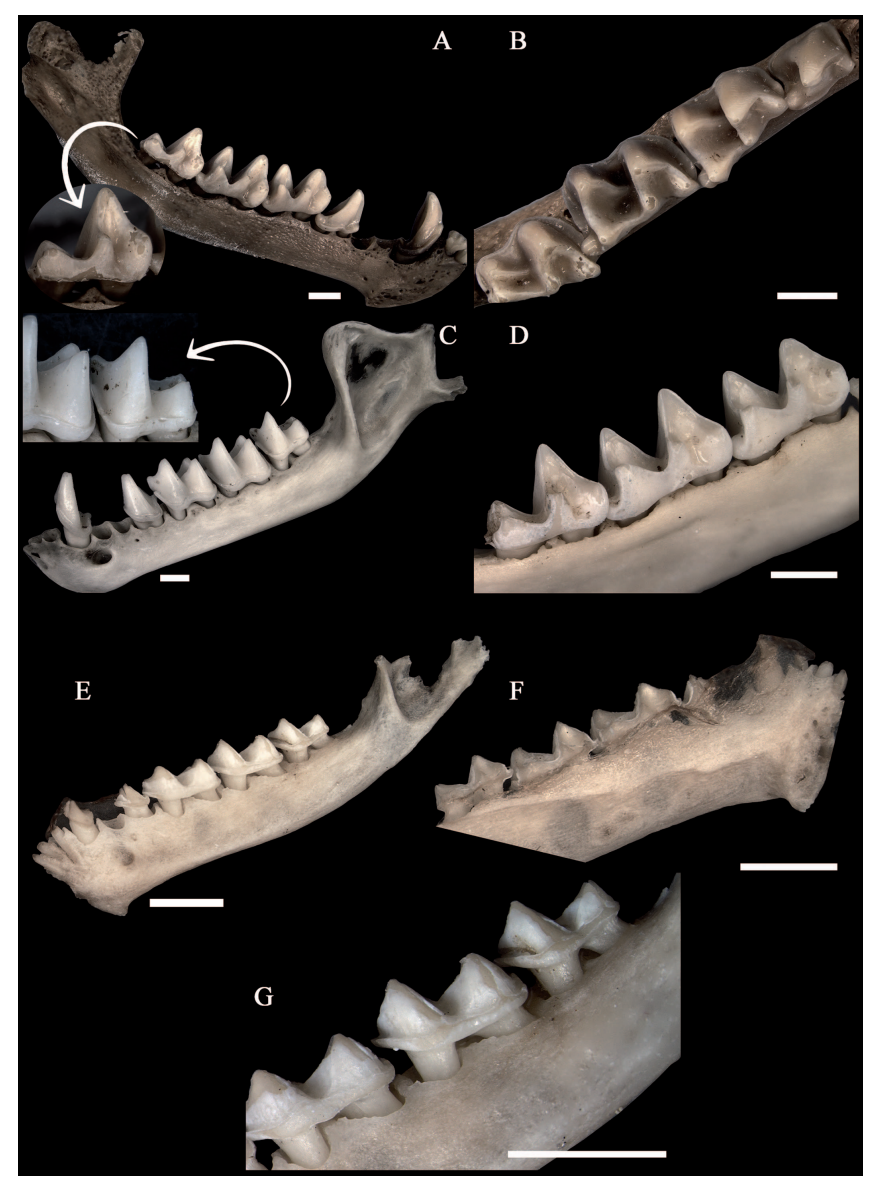

Figura 9. Hemimandíbulas del Grupo 2 expuestas a la enzima Pronase. a-b) Myotis myotis juvenil; Flecha: detalle de la vista lingual de $\mathrm{M}_{3}$. c-d) Myotis myotis adulto; Flecha: detalle de la vista labial de $\mathrm{M}_{3}$. e-g) vistas labial, lingual y acercamiento de la vista labial de Pipistrellus pipistrellus. Escalas $=1 \mathrm{~mm}$.

estadio de la secuencia, el "Estadio 4". En este caso, la dentición maxilar de P. pipistrellus del Grupo 1, tras la exposición enzimática con Pronase, fue la que mostró la mayor modificación.

Los dientes sueltos de M. myotis mostraron mayor alteración que la dentición in situ por lo que se han utilizado para establecer los estadios intermedios de la secuencia para la dentición superior.

La dentición mandibular mostró diferencias en los grados de modificación tanto en la variable tamaño como en la edad y enzima utilizada. Por ello pudimos establecer con ellas los 4 estadios de la secuencia de modificación para la dentición inferior.

Las cápsulas óticas mostraron un claro patrón de modificación secuencial después del experimento, donde primeramente se ven afectados los bordes del canal semicircular superior. Luego ocurre la disolución parcial del canal semicircular lateral y finalmente la disolución parcial del canal semicircular superior y disolución total de los canales laterales y posterior. 
Tabla 3. Tabla de la posible secuencia de progresión de las modificaciones ocurridas en dientes de murciélagos a causa de la digestión. Esta secuencia fue establecida a partir de las modificaciones diferenciales observadas en los elementos craneales (dentición in situ, dientes sueltos, capsulas óticas) de murciélagos, después de la exposición al ataque ácido-enzimático experimental. Se han establecido 4 estadios en la secuencia de modificación. c/ = con.

\begin{tabular}{|c|c|c|c|}
\hline & Estadio 1 & Estadio 2 & Estadio 3 \\
\hline \multirow{6}{*}{ Criterios } & Superiores: & Superiores: & Superiores: \\
\hline & $\begin{array}{l}\text { Hemimaxilas de } M . \text { myotis } \\
\text { Juvenil c/ Pronase }\end{array}$ & $\begin{array}{l}\text { Dientes sueltos (caninos, P4 y } \\
\text { molares) c/ Olexa }\end{array}$ & Dientes sueltos c/ Pronase \\
\hline & $\begin{array}{l}\text { Hemimaxilas de } M \text {. myotis } \\
\text { Adulto c/ Olexa y Pronase }\end{array}$ & $\begin{array}{l}\text { Hemimaxila de } P \text {. pipistrellus } \mathrm{c} / \\
\text { Olexa }\end{array}$ & \\
\hline & Inferiores: & Inferiores: & Inferiores: \\
\hline & $\begin{array}{l}\text { Hemimandíbula de } M \text {. myotis } \\
\text { adulto y juvenil c/ Olexa }\end{array}$ & Dientes sueltos c/ Olexa & Dientes sueltos en Pronase \\
\hline & & $\begin{array}{l}\text { Hemimandíbula de } M \text {. myotis } \\
\text { adulto y juvenil c/ Pronase. }\end{array}$ & $\begin{array}{l}\text { Hemimandíbula de } P \text {. } \\
\text { pipistrellus } \mathrm{c} / \text { Olexa }\end{array}$ \\
\hline $\begin{array}{l}\text { Caninos y } \\
\text { premolares }\end{array}$ & $\begin{array}{l}\text { Diente con superficie mate. } \\
\text { Puede presentarse solo en la cara } \\
\text { labial (Fig. } 8 \mathrm{a} ; \text { P4) o únicamente } \\
\text { en la faceta de desgaste (Figs. } \\
6 \mathrm{c}, 7 \mathrm{c} \text { ). }\end{array}$ & $\begin{array}{l}\text { Lateral: Pérdida de esmalte parcial } \\
\text { en la base de la corona (Figs. } 4 \mathrm{~b} \text {, } \\
\text { 4f, 6e). Pérdida de esmalte en el } \\
\text { cíngulo desde parcial hasta completa } \\
\text { con disolución de la dentina (Figs. } \\
\text { 4f-h). Ángulos agudos con banda } \\
\text { de dentina (Figs. } 4 \mathrm{e}, 4 \mathrm{~h} \text { ), acentuada } \\
\text { si existe desgaste dental (Fig. 6e). } \\
\text { Disolución parcial de raíces abiertas } \\
\text { en dientes sueltos. } \\
\text { Oclusal: Pérdida de esmalte con } \\
\text { exposición de la dentina en todas } \\
\text { las cúspides. }\end{array}$ & $\begin{array}{l}\text { Lateral: Superficie mate en la } \\
\text { cara labial y pérdida del esmalte } \\
\text { de cíngulo por la cara lingual. } \\
\text { (Figs.8e-g). En dientes sueltos, } \\
\text { desde pérdida de esmalte } \\
\text { alrededor de toda la base } \\
\text { coronaria (Fig. 2) hasta pérdida } \\
\text { de esmalte por una de sus caras } \\
\text { (Fig. 2a). Cíngulo con pérdida } \\
\text { de esmalte con disolución de } \\
\text { la dentina. Pérdida completa de } \\
\text { raíces abiertas (dientes huecos). } \\
\text { Pérdida de esmalte en cúspide } \\
\text { y borde incisal, tanto en dientes } \\
\text { sueltos como in situ. }\end{array}$ \\
\hline
\end{tabular}

Lateral: Cara labial con Lateral: Desde picoteado (Figs. 6e- Lateral: Pérdida total de esmalte superficie mate (Fig. 7c). En f), hasta pérdida de esmalte en la dientes sin desgaste superficie base coronaria (Figs. 5a-f), en la cara mate por la cara lingual, labial. Banda de dentina incompleta borde anguloso del cíngulo en mesostilo en la cara labial (Fig. y postprotocresta (Fig. 7b). 5b) y completa en cara lingual de Oclusal: Dientes con desgaste dientes posteriores (Fig. 6f). Pérdida

Molares superiores presentan superficie mate en crestas (ej. Fig. 6c-d) y pérdida de esmalte en el borde interno de la faceta de desgaste del protocono (Figs. 6d, 7d).

Lateral: Cara labial con superficie mate (Figs. 8a-b). Dientes posteriores con picoteado del esmalte en su cara lingual (Fig. $8 \mathrm{c} ; \mathrm{M}_{2}$ y $\left.\mathrm{M}_{3}\right) . \mathrm{M}_{3}$ con pérdida de esmalte formando una banda de dentina incompleta en el

Molares inferiores metacónido (Fig. 8c).

Oclusal: Pérdida de esmalte en cúspides y borde interno de las facetas de desgaste en dientes posteriores que presentan desgaste (Fig. 8d; $\mathrm{M}_{2} \mathrm{y} \mathrm{M}_{3}$ ).

\section{de esmalte completa en cíngulo.}

Oclusal: Pérdida de esmalte en algunas cúspides (Figs. 5a-c). Esmalte de las crestas muestran desde picoteado (Fig. 5a), hasta pérdida en el borde interno de la faceta de desgaste (Fig. 6e-f). en la cara labial (Figs. 3 b, 3e).

Banda de dentina incipiente en protocono (cara lingual) (Fig. 3a). Disolución del cíngulo (Figs. 3a-f).

Oclusal: Pérdida del esmalte en todas las cúspides y a lo largo de las crestas. En valles, desde pérdida de esmalte alrededor de las crestas (Fig. 3e) hasta islas de esmaltes (Fig. 3b). Pérdida completa de la raíz en dientes sueltos (dientes huecos).

Lateral: Pérdida parcial del esmalte Lateral: Cara lingual con pérdida en cíngulo en su cara labial. La total (Figs. 3h, 3k) o islas de corona presenta, por su cara lingual, esmalte (Fig. 8g). Dientes desde picoteado con pérdida de sueltos con cíngulo parcialmente esmalte en su base (Figs. 9a, 5k) disuelto y sin esmalte (Fig. 3g) o hasta banda de dentina en molar con bien presentando islas de esmalte desgaste (Figs. 5h, 9d) Oclusal: Pérdida de esmalte en todas las cúspides, incluyendo crestas (Figs. 9b, 9d). En dientes con desgaste (Fig. 9d), pérdida de esmalte, total o parcial en valle del trigónido. Dientes sueltos con pérdida de esmalte en los estilos (Figs. 5h, 5k).

$\begin{array}{ll}\text { Cápsula } & \text { Disolución en los bordes finos/ } \\ \text { ótica } & \text { agudos del canal semicircular } \\ & \text { superior (Figs. 10a-b). }\end{array}$

Disolución parcial del canal semicircular lateral (Figs. 10c-d).
Lateral: Desde esmalte fuertemente picoteado con pérdida de esmalte en cíngulo y ángulos salientes (Figs. 7ef), hasta pérdida total (caninos) o casi total (premolares) del esmalte con disolución de la dentina (Figs. 9e-f).

Lateral: Cara labial fuertemente picoteada y diente posterior $\left(\mathrm{M}^{3}\right)$ desprovistos completamente de esmalte. La cara lingual presenta pérdida de esmalte en el cíngulo y bandas de dentina tanto en proto como en metacónulo.

Oclusal: Pérdida de esmalte en cúspides y crestas. Además, los valles del paracono y metacono pueden presentar islas de esmalte o haberlo perdido por completo (Figs. 7e-g)

Lateral: Cara lingual pérdida total del esmalte con disolución de la dentina (Fig. 9f). Banda de dentina y pérdida del esmalte en cíngulo encara labial (Figs. 9e, 9g).

Oclusal: El valle del trigónido ha perdido todo el esmalte en el valle (Fig. 9f). 

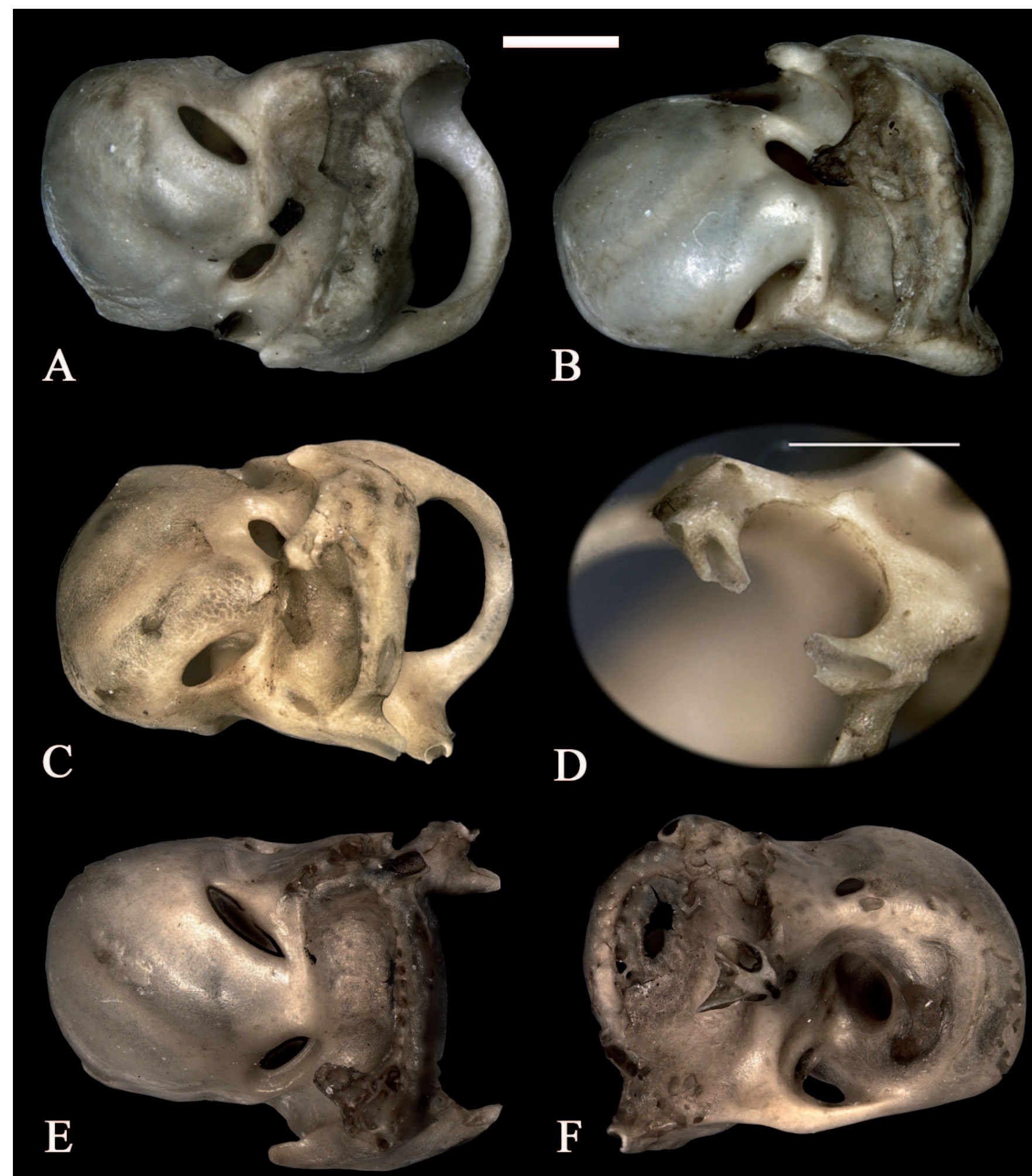

Figura 10. Capsulas óticas de Myotis myotis. a) individuo adulto expuesto a Olexa (Grupo 2). b) individuo juvenil expuesto a Olexa (Grupo 2). c) individuo adulto expuesto a Pronase (Grupo 1). d) detalle de (c), canal semicircular lateral disuelto. e) individuo juvenil expuesto a Pronase (Grupo 1). f) detalle de E, canales semicirculares lateral y posterior disueltos. Escalas $=1 \mathrm{~mm}$. 


\subsection{Elementos postcraneales}

Solamente los húmeros y fémures del Grupo 1 presentaron modificaciones. En fémures, la modificación se presenta como pérdida de hueso compacto, con exposición de las trabéculas del tejido esponjoso en la epífisis proximal, viéndose más afectada la cabeza femoral que los trocánteres. En húmeros, en cambio, la modificación observada en la epífisis distal (donde Andrews en 1990 ha caracterizado la alteración por digestión en roedores) es más leve que en fémures, presentando algunas perforaciones en el cóndilo humeral y adelgazamiento del hueso compacto con perforación en la tróclea. El hueso esponjoso no se ve extensamente expuesto, como ocurre en la articulación proximal, tubérculos y cresta deltoide de la epífisis proximal humeral.

\section{DISCUSIÓN Y CONCLUSIONES}

Una vez establecida la secuencia de modificación, podemos decir que la dentición maxilar de Myotis myotis mostró escasa diferencia en las modificaciones provocadas por las distintas enzimas, existiendo diferencias entre adultos y juveniles por la diferencia de desgaste dental. Es posible que este desgaste constituya una zona de debilidad en el esmalte que permite que los ácidos y enzimas pueden actuar con mayor eficacia. La dentición maxilar de Pipistrellus pipistrellus, por su lado, mostró diferencias evidentes según la enzima a la que fue expuesta, indicando que ambas enzimas, Olexa y Pronase, alteran diferencialmente. Sin embargo, la dentición maxilar de $P$. pipistrellus también mostró diferencias evidentes respecto de los ejemplares de $M$. myotis, sometidos a las mismas condiciones experimentales, lo que apunta a que el tamaño es una variable importante a tener en cuenta. La influencia del tamaño de los individuos y del desgaste de los elementos dentarios son aspectos de interés que requieren mayor estudio.

La dentición maxilar mostró, en todos los casos, mayor resistencia que la mandibular al ataque ácido-enzimático provocado en el experimento, ya que se produjeron modificaciones más intensas en la dentición mandibular bajo las mismas condiciones experimentales. Esto es una excepción respecto a las muestras de roedores digeridas por rapaces, ya que sus maxilares, al ser más porosos, presentan habitualmente una mayor permeabilidad a los jugos gástricos y, por tanto, mayores efectos de digestión (Andrews, 1990). Es probable que exista una diferencia de grosor del esmalte entre los dientes superiores e inferiores de quirópteros y esto produzca la modificación diferencial.

La modificación más leve observada se corresponde con una superficie mate, que se presenta en la cara lingual de molares superiores y la cara labial en inferiores. Sin embargo, en individuos adultos se presenta en las crestas, asociadas al desgaste dental, acompañada de pérdida de esmalte en los bordes internos de las facetas de desgaste. Esto indica una mayor probabilidad de identificar los primeros grados de digestión en molares que presenten algún nivel de desgaste, ya que la superficie mate en los fósiles puede darse por otros procesos postdeposicionales, como la exposición subaérea, los rayos UV o la exposición a suelos, tanto ácidos como alcalinos (Andrews, 1990; Fernández-Jalvo et al., 2002).

Las modificaciones más evidentes, como la pérdida de esmalte, se manifiestan en primera instancia en el tercer molar. Posteriormente, la modificación se extiende progresivamente hacia el primer molar, tanto en la dentición superior como en la inferior. Si estas modificaciones ocurren de manera similar en la naturaleza los molares posteriores serían más identificativos de digestión en caso de obtener únicamente dientes sueltos. Además, en la dentición maxilar la pérdida del esmalte se produce en la cara labial en los estadios iniciales, para luego producirse en la cara lingual en los estadios más avanzados. En la dentición mandibular en cambio, la pérdida del esmalte progresa en la dirección opuesta.

En los yacimientos donde existe registro de murciélagos, en ocasiones es posible registrar dientes sueltos que se encuentran huecos. Estos son con frecuencia atribuidos a individuos infantiles (pocos días de vida) que no lograron sobrevivir y al no haber desarrollado aún las raíces de la dentición definitiva producen dientes sueltos huecos. Ahora, con relación a los dientes sueltos del experimento, observamos que las enzimas podrían causar disolución completa de las raíces de dientes definitivos de individuos juveniles. Así, estos dientes huecos, podrían ser parte del contenido de egagrópilas de rapaces oportunistas que cazan murciélagos dentro de las parideras durante el período de reproducción (Garrido-García \& Nogueras, 2007). Esto implicaría, además, que podría distinguirse la dentición que se ha desprendido durante la ingestión y digestión dentro de una asociación. Así, observando si la corona presenta alguna de las modificaciones encontradas en este trabajo, se podría distinguir entre ambos escenarios, es decir, entre elementos producidos por muerte in situ de infantes de pocos días de vida y elementos producidos por depredación.

La cápsula ótica es un elemento bastante desarrollado en quirópteros, sin embargo, su presencia en yacimientos fósiles con murciélagos es bastante escasa (o es obviada en el conteo de elementos esqueléticos). Al observar las modificaciones encontradas, podemos concluir que este elemento no es lo suficientemente frágil para ser disuelto por la acción ácido-enzimática. Así, su ausencia en los yacimientos con restos de murciélagos podría ser indicativo de acción de procesos post-deposicionales como transporte o pisoteo. Es necesario realizar estudios de egagrópilas 
que contengan cápsulas óticas para poder corroborar si las modificaciones encontradas responden al grado de disolución provocado por la digestión o al diferente grado de osificación entre individuos adultos y juveniles.

Con respecto al esqueleto postcraneal, después del experimento observamos efectos de la acción ácidoenzimática en el proximal de fémur y distal de húmero, presentando un patrón de modificación similar al descrito en la literatura para la digestión en roedores (Andrews, 1990; Denys, 1995). Es necesario realizar más experimentos con elementos postcraneales para establecer una secuencia de modificaciones y sus diferentes grados de alteración.

Las modificaciones obtenidas con la enzima Olexa preparada con $\mathrm{HCl}$ han resultado menos intensas que las obtenidas con la enzima Pronase. Además, Olexa produjo modificación principalmente en la dentición, sin producir alteraciones en elementos postcraneales y en los huesos mandibular y maxilar.

Es necesario realizar muestras de control con micromamíferos cuyas modificaciones estén descritas en la literatura (arvicólidos, múridos, sorícidos, etc.) (FernándezJalvo et al., 2016, 2017), además de estudios actualistas con egagrópilas y excrementos de diferentes depredadores, para conocer el grado de digestión (Andrews, 1990) al que se corresponden las modificaciones provocadas en este experimento y poder así correlacionar las categorías de digestión en roedores, sorícidos y quirópteros.

\section{AGRADECIMIENTOS}

Este trabajo fue financiado por AJISEP de la Sociedad Española de Paleontología, CGL2016-79334P del Programa Estatal de Fomento de la Investigación Científica y Técnica de Excelencia del Gobierno de España y CONICYT BECASCHILE 79090016 del Gobierno de Chile. Gracias a José Antonio Vallejos por proporcionar los quirópteros juveniles actuales utilizadas en este trabajo. También extender las gracias a Lorena Díez de UNIVAR por su gestión y a Novozymes por haber proporcionado la enzima Olexa para el experimento realizado en este trabajo. Gracias al Laboratorio de Tafonomía Experimental del MNCN de Madrid dónde se realizó parte del experimento. También agradecemos las sugerencias y comentarios hechos por Vicente Crespo y un revisor anónimo, que mejoraron en gran medida la primera versión de este manuscrito. Finalmente, queremos agradecer especialmente a Isabel Bermúdez de Castro que nos ayudó y supervisó en todo momento con su amabilidad característica, durante la preparación de las enzimas en el laboratorio de Biología Molecular en el MNCN-CSIC.

\section{REFERENCIAS}

Andrews, P. 1990. Owls, Caves and Fossils. Natural History Museum Publications, London.

Boblitt, C.M., Plotnick, R.E., Kening, F. \& Meyer-Dombard, D. 2018. Determining taphonomic controls and rates of decay in cave environments using microcosms. Palaios, 33, 141-153; doi: 10.2110/palo.2017.047.

Crandall, B.D. \& Stahl, P.W. 1995. Human digestive effects on a micromammalian skeleton. Journal of Archeological Science, 22, 789-797; doi: 10.1016/0305-4403(95)90008-X.

Denys, C. 1985. Nouveaux critères de reconaissance des concentrations de microvertébrés d'aprés l'étude des pelotes de chouettes du Bostwana (Afrique australe). Bulletin Muséum National d'Historie Naturelle, 4, 879933.

Denys, C., Fernández-Jalvo, Y. \& Dauphin, Y. 1995. Experimental taphonomy: preliminary results of the digestión of micromammal bones in the laboratory. Comptes Rendus de l'Académie des Sciences, 321, 803809.

Dodson, P. \& Wexlar, D. 1979. Taphonomic investigation of owl pellets. Paleobiology, 5, 275-284.

Fernández, F.J., Montalvo, C.I., Fernández-Jalvo, Y., Andrews, P. \& López, J.P. 2017. A re-evaluation of the taphonomic methodology for the study of small mammal fossil assemblages of South America. Quaternary Science Reviews, 155, 37-49; doi: 10.1016/j.quascirev.2016.11.005.

Fernández-Jalvo, Y. \& Andrews, P. 1992. Small mammal taphonomy of gran Dolina, Atapuerca, Spain. Journal Archaeological Science, 19, 407-428; doi: 10.1016/03054403(92)90058-B.

Fernández-Jalvo, Y., Denys, C., Andrews, P., Williams, T., Dauphin, Y. \& Humpherey, L. 1998. Taphonomy and Palaeoecology of Olduvai Bed-I (Pleistocene, Tanzania). Journal of Human Evolution, 37, 137-172; doi: 10.1006/ jhev.1997.0188.

Fernández-Jalvo, Y., Sánchez-Chillón, B., Andrews, P., Fernández-López, S. \& Alcalá Martínez, L. 2002. Morfological taphonmic transformations of fossil bones in continental environments, and repercussions on their chemical composition. Archeometry, 44, 353-361; doi: 10.1111/1475-4754.t01-1-00068.

Fernández-Jalvo, Y., Andrews, P., Sevilla, P. \& Requejo V. 2014. Digestion versus abrasion features in rodent bones. Lethaia, 47, 323-336; doi: 10.1111/let.12061.

Fernández-Jalvo, Y., Andrews, P., Denys, C., Sesé, C., Stoetzel, E., Marin-Monfort, D. \& Pesquero, D. 2016. Taphonomy for taxonomists: Implications of predation in small mammal studies. Quaternary Science Reviews, 139, 138-157; doi: 10.1016/j.quascirev.2016.03.016.

Fisher, D.C. 1981. Crocodilian scatology, microvertebrate concentrations and enamel-less teeth. Paleobiology, 7, 262-275.

Garrido-García, J. \& Nogueras, J., 2007. Myotis myotis. En: Atlas y Libro Rojo de los Mamíferos Terrestres de España (eds. Palomo, J., Gisbert, J. \& Blanco, J.C.). Ministerio de Medio Ambiente, Madrid, 153-157. 
Hill, J.E. \& Smith, J.D. 1984. Bats: A Natural History. London: British Museum of Natural History.

Kowalski, K. 1995. Taphonomy of bats (Chiroptera). Geobios, 18, 251-256; doi: 10.1016/S0016-6995(95)80172-3.

Lowe, V.P.W. 1980. Variation in digestion of prey by the Tawny owl (Strix aluco). Journal of Zoology, 192, 283293; doi: 10.1111/j.1469-7998.1980.tb04234.x.

Mellett, J. 1974. Scatological origin of microvertebrate fossil accumulation. Science, 185, 349-350; doi: 10.1126/ science.185.4148.349.

Pérez Barbería, F.J. 1991. Influencia de la variación latitudinal en la contribución de los murciélagos (Chiroptera) a la dieta de la lechuza común (Tyto alba). Ardeola, 38, 61-68.

Pérez Ripol, M. 2016. Los niveles de corral en el yacimiento neolítico de la Cova de l'Or, sectores K34, K35 y K36. Información aportada por el estudio de la fauna. In: Del Neolític a l'Edat dell Bronze en el Mediterrani Occidental. Estudis en Homenaje a Bernat Martí Oliver (eds. Bonet Rosado, H. \& Martí Oliver, B.). SIP, Valencia, 117-124.

Raczynski, J. \& Ruprecht, A.L. 1974. The effects of digstion on the osteological composition of owl pellets. Acta Ornitologica, 14, 1-12.

Rosina, V.V. \& Shokhrin, V.P. 2011. Bats in the diet of owls from the Russian Far East, southern sikhote alin. Hystrix the Italian Journal of Mammalogy, 22, 205-213.
Ruprecht, A.L. 1979. Bats (Chiroptera) as constituents of the food of barn owls Tyto alba in Poland. Ibis, 121, 489-494; doi: 10.1111/j.1474-919X.1979.tb06690.x.

Schreber, J.C.D.V. 1774. Die Säugethiere in Abbildungen nach der Natur mit Beschreibungen. Erster Theil. Der Mensch. Der Affe. Der Maki. Die Federmaus. Walther, Erlangen.

Sevilla, P. 1988. Estudio paleontológico de los quirópteros del Cuaternario español. Pelontologia i Evolució, 22, 113-233.

Smith, C.R. \& Richmond, M.E. 1972. Factors influencing pellet egestion and gastric $\mathrm{pH}$ in the barn owl. The Wilson Bulletin, 84, 179-186.

Sommer, R., Zoller, H., Kock, D., Böhme, W. \& Griesau, A. 2005. Feeding of the barn owl, Tyto alba, with first record of the European free-tailed bat, Tadarida teniotis on the island of Ibiza (Spain, Balearics). Folia Zoologica, 54, 364-370.

Terry, R.C. 2004. Owl pellet taphonomy: a preliminary study of the post-regurgitation taphonomic history of pellet in a temperate forest. Palaios, 19, 497-506; doi: 10.1669/0883-1351(2004)019<0497:OPTAPS>2.0.CO;2.

Williams, J.P. 2001. Small mammal deposits in archaeology a taphonomic investigation of Tyto alba (barn owl) nesting and roosting sites. Ph.D. Thesis, University of Sheffield, Department of Archaeology and Prehistory. 
